\title{
Carcinoma da mama com diferenciação coriocarcinomatosa
}

Claudia Rossetti'; Renata Silvia Sacchi²; Virginia Berlanga Campos Junqueira ${ }^{3}$; Fernando Luiz Affonso Fonseca ${ }^{4}$

\begin{tabular}{l|l}
\multicolumn{1}{c|}{ unitermos } & resumo \\
Carcinoma & $\begin{array}{l}\text { O presente relato descreve um caso de carcinoma mamário em paciente de } 45 \text { anos, com diferenciação } \\
\text { coriocarcinomatosa, caracterizado por presença de células bizarras, anaplásicas, com áreas de necrose } \\
\text { Mama }\end{array}$ \\
$\begin{array}{l}\text { Características } \\
\text { coriocarcinomatosas } \\
\text { coriônica humana ( } \beta \text {-HCG) e cromogranina, medindo 5,7 cm no maior eixo, refratário ao tratamento } \\
\text { neoadjuvante inicial. Realizada mastectomia, cujo diagnóstico após análises microscópica e imuno- } \\
\text { histoquímica concluiu tratar-se de carcinoma com características coriocarcinomatosas. Tais lesões são } \\
\text { raras, capazes de sintetizar substâncias hormonais não próprias ao tecido mamário, sendo o diagnóstico } \\
\text { de grande importância para a abordagem terapêutica e prognóstica, pois constituem um grupo de } \\
\text { lesões potencialmente agressivas. }\end{array}$
\end{tabular}

\section{abstract}

This report describes the case of a 45 year-old patient with breast carcinoma characterized by choriocarcinomatous features, presence of bizarre anaplastic cells with areas of necrosis and multinucleated giant cells. The immuno-histochemical analysis showed positivity for chromogranin and $\beta$-HCG. The tumor size was $5.7 \mathrm{~cm}$ at the largest axis and it was refractory to initial neo-adjuvant treatment. Mastectomy was performed and after microscopic and immuno-histochemical examination it was diagnosed as carcinoma with choriocarcinomatous features. These lesions are rare and liable to synthesize hormonal substances not specific to breast tissue. Its diagnosis is highly significant to the therapeutic and prognostic approach insofar as these lesions are potentially aggressive.
Primeira submissão em 20/07/09 Última submissão em 15/12/09 Aceito para publicação em 15/12/09 Publicado em 20/12/09

\section{Breast cancer with choriocarcinomatous features}




\section{Introdução}

Carcinomas com diferenciação coriocarcinomatosa constituem um grupo raro e heterogêneo de neoplasias mamárias com características de produção neuroendócrina, os quais são inclusos por alguns autores ao grupo dos carcinomas metaplásicos, estes correspondendo a menos de $5 \%$ dos carcinomas da mama ${ }^{(5,8)}$. Caracterizam-se pela presença de células neoplásicas que manifestam a capacidade de sintetizar uma série de substâncias hormonais, não próprias do tecido mamário(5).

Cerca de $12 \%$ a $18 \%{ }^{(9)}$ dos carcinomas da mama podem expressar positividade para a subunidade $\beta$ da gonadotrofina coriônica humana ( $\beta$-HCG) identificada após utilização de estudo imuno-histoquímico, mostrando positividade fraca e focal.

A diferenciação coriocarcinomatosa foi primeiramente descrita por Saigo e Rosen ${ }^{(9)}$ como uma variante distinta dos carcinomas mamários, com capacidade de produção de substâncias hormonais ectópicas, aspecto histológico e prognóstico distintos das demais lesões mamárias neoplásicas frequentes, daí a referência como carcinoma metaplásico pertencente ao subgrupo de neoplasias com diferenciação neuroendócrina. Tais alterações têm sido manifestadas conjuntamente com a produção de substâncias ectópicas em quantidade suficiente para sua detecção, substâncias estas estranhas ao tecido de origem ${ }^{(9)}$.

Estruturalmente, quanto aos carcinomas com diferenciação coriocarcinomatosa, as alterações correspondem a manifestações fenotípicas morfológicas que, neste caso, assemelham-se a neoplasias originárias do tecido placentário.

\section{Relato de caso e métodos}

Relatamos o caso de uma paciente de 45 anos de idade, quatro gestações, quatro partos cesáreos, hipertensa e com história de carcinoma mamário em tia materna. Em 2005, junto à unidade de atendimento primário, foi identificada lesão em mama esquerda há quatro meses, cujo aspecto mamográfico apresentava-se como nódulo hiperdenso, medindo 5,7 cm no maior eixo, localizado na intersecção de quadrantes superiores, com contornos bosselados e ausência de microcalcificações, com provável diagnóstico de tumor filodes. A paciente foi encaminhada ao serviço de Mastologia do Hospital Estadual Mario Covas, onde se evidenciou nódulo em mama esquerda com história de aproximadamente um ano, indolor e sem descarga papilar associada.
Ao exame físico identificou-se nódulo de $10 \mathrm{~cm} \times 5 \mathrm{~cm}$, móvel e axila negativa, caracterizado, segundo o padrão de classificação breast imaging reporting and data system (BI-RADS), em nível 4.

Foi realizada biópsia por agulha grossa, sendo diagnosticado carcinoma pouco diferenciado, grau III nuclear, com presença de células bizarras.

Encaminhada ao serviço de oncologia, a paciente foi submetida a quimioterapia neoadjuvante com quatro ciclos de adriamicina + ciclofosfamida e três ciclos de taxol, seguida de radioterapia, a qual não expressou resposta clínica, provocando, contudo, ulceração e necrose da pele após o ciclo radioterápico ("tumor em couraça").

Após tais procedimentos, retornou ao serviço de mastologia para realização de mastectomia higiênica, sendo o espécime cirúrgico enviado ao Departamento de Anatomia Patológica para ser submetido a análises macro e microscópica.

\section{Resultados}

No espécime identificou-se lesão esbranquiçada, granulosa, com ulceração da pele e bordos sobrelevados, não mensurável, posto que o material mostrava-se intensamente fragmentado pela dificuldade de excisão cirúrgica. Aos cortes a lesão mostrava-se esbranquiçada, friável e com focos hemorrágicos.

O exame microscópico demonstrou a presença de carcinoma mamário invasivo, grau III de Notthingham, grau III nuclear, constituído em grande parte por células bizarras, por vezes multinucleadas, intensa anaplasia em meio a tecido necrótico com focos de hemorragia (Figura 1). O estudo imuno-histoquímico demonstrou receptores de estrógeno e progesterona negativos, intensa positividade para proteína p63, vimentina positiva nas células neoplásicas, positividade para cromogranina (Figura 2) e positividade focal para $\beta$-HCG (Figura 3).

Não foi possível a realização de dosagem sanguínea de $\beta$-HCG devido ao fato de a paciente ter sido submetida a tratamento quimioterápico neoadjuvante seguido de excisão cirúrgica (mastectomia modificada à Madden) devido à não responsividade ao tratamento proposto e à rápida evolução da lesão.

Conclui-se, portanto, somados os aspectos histológicos ao perfil imuno-histoquímico, tratar-se de carcinoma mamário com diferenciação coriocarcinomatosa, afastando-se a 
possibilidade de anaplasia nuclear induzida por radioterapia, posto que, no material inicial proveniente de biópsia por agulha grossa, a lesão já exibia tais características.

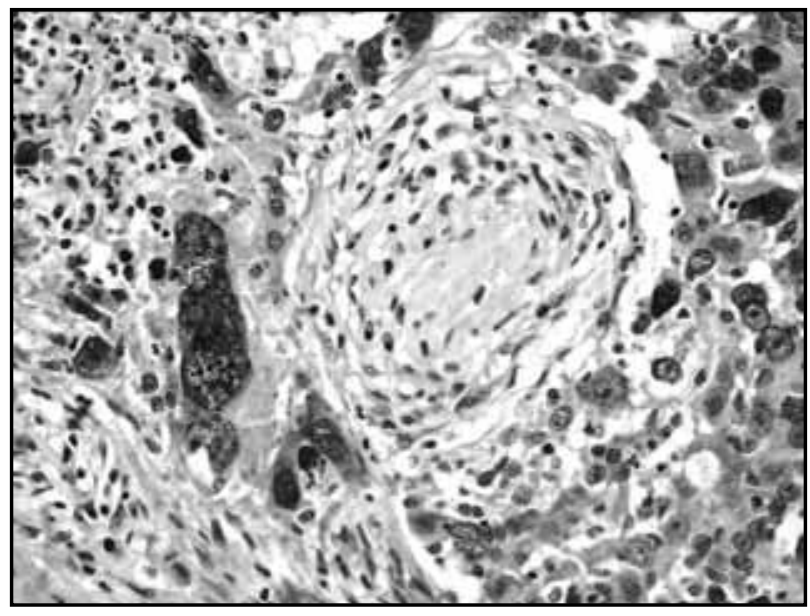

Neoplasia constituída por células bizarras por vezes multinucleadas (HE 400x)

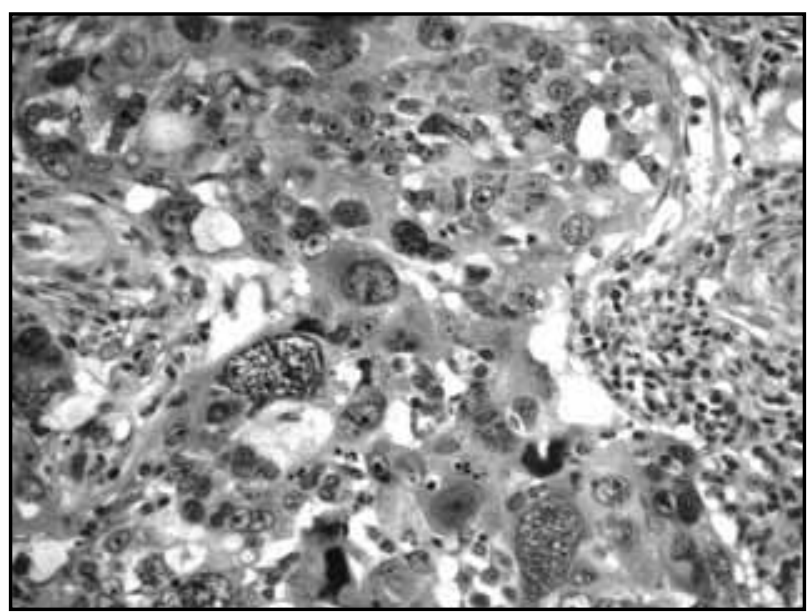

Figura 2 - Positividade citoplasmática para cromogranina (IHQ 400x)

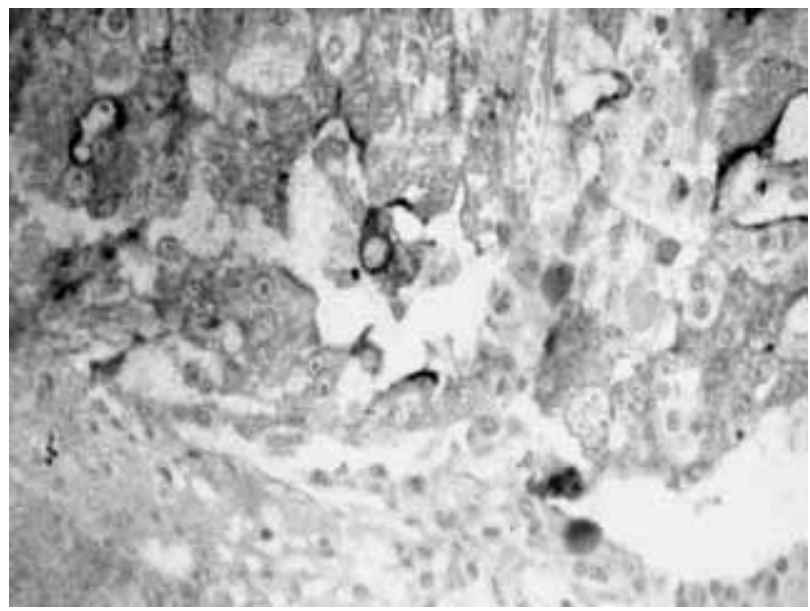

Figura 3 - Positividade para $\beta$-HCG (IHQ 400x)

\section{Discussão}

O aspecto histológico conferido é certamente consequência de alterações genéticas envolvendo, em parte, repressões dos mecanismos de codificação moleculares normais, que são requeridos para a produção de proteínas que contribuem para o fenótipo epitelial.

Seu componente coriocarcinomatoso possui alterações que lhe conferem a capacidade de produção de substâncias ectópicas em quantidade suficiente para sua detecção tanto em análises bioquímicas como imuno-histoquímicas ${ }^{(10)}$.

As alterações estruturais manifestam-se por aspectos fenotípicos morfológicos que, por exemplo, podem lembrar tumores carcinoides, ou coriocarcinomas, portanto com diferenciação neuroendócrina, bem como uma variedade de substâncias hormonais, hormônio adrenocorticotrófico $(\mathrm{ACTH})^{(2,13)}$ e lactogenina placentária( ${ }^{(6)}$, substâncias estas consideradas não usuais à glândula mamária( ${ }^{(4)}$, subclassificadas, portanto, como lesões pertencentes ao grupo dos carcinomas metaplásicos e subgrupo relativo aos tumores com características neuroendócrinas. No caso relatado, classificamos as lesões como coriocarcinomatosas devido ao aspecto fenotípico morfológico e à capacidade de produção de substâncias não próprias ao tecido mamário normal, o que, segundo a literatura, deve ser subclassificado como lesão com aspectos neuroendócrinos. A positividade para p63 reflete uma característica dos carcinomas metaplásicos, grande parte deles pertencente ao grupo dos carcinomas de origem basal da mama, os quais expressam marcadores de células mioepiteliais como EGFR, CK 5/6, vimentina e p63.

Geralmente, lesões com diferenciação coriocarcinomatosa apresentam-se bem delimitadas e axila-negativas, uma característica dos carcinomas metaplásicos, e, ainda, pode ser identificada isoladamente, ou em associação a adenocarcinomas originários do trato gastrointestinal(4).

Nesses casos, em que há diferenciação coriocarcinomatosa, tais alterações estão associadas em $95 \%$ dos casos, segundo Torney et al. ${ }^{(12)}$, a elevados níveis de $\beta$-HCG no sangue.

Citologicamente, o aspirado demonstra presença de células multinucleadas, que podem ser encontradas tanto em lesões benignas como malignas, mas, nos casos malignos, associam-se a marcada atipia nuclear e fundos hemorrágico e necrótico $(1,7,11)$.

Essas lesões geralmente mostram prognóstico sombrio e curso agressivo, cujas pacientes evoluem com múltiplas metástases em curto espaço de tempo, sendo a via hema- 
togênica a preferencial para a disseminação da neoplasia, cujos sítios metastáticos preferenciais incluem pulmão, sistema nervoso central (SNC) e fígado.

A negatividade frequente para receptores hormonais, bem como para c-erbB-2, não possui alvos terapêuticos visados, sendo muitas vezes os tratamentos químio e radioterápico não responsivos. Contudo, com o avanço nas pesquisas quanto a novas possibilidades terapêuticas, vislumbra-se o papel dos bloqueadores do fator de crescimento epidérmico (EGFR) e do receptor do fator de crescimento de vasos (VGFR) como tratamentos futuramente promissores.

A etiologia de tais lesões possivelmente se daria devido aos processos de alterações genotípicas e fenotípicas que ocorrem nas mesmas, cujo resultado seria a transformação parcial ou completa das células neoplásicas em um componente coriocarcinomatoso, com capacidade de sintetizar substâncias hormonais próprias, como o $\beta$-HCG.

\section{Conclusões}

Claramente, os carcinomas mamários têm potencial para uma extensa variedade de expressões químicas e morfológicas.

Esses tumores são raros, portanto a decisão para o tratamento baseia-se em dados retrospectivos, sendo comumente adotada a mastectomia como tratamento mais apropriado. Entretanto, novas drogas estão sendo utilizadas e testadas para carcinomas com características basais, ou seja, carcinomas originários de stem cells, cuja expressão imuno-histoquímica inclui CK5/6, CK14, EGFR, vimentina, p63 e p-caderina, cujos resultados mostram-se promissores, tornando-se uma alternativa para as pacientes, cujo prognóstico quanto à sobrevida tem variado de dois a quatro anos(3).

\section{Referências}

1. AKBULUT, M. et al. Fine needle aspiration cytology of mammary carcinoma with choriocarcinomatous features: a report of 2 cases. Acta Cytol, v. 52, n. 1, p. 99-104, 2008.

2. COHLE, S. D. et al. ACTH: secreting carcinoma of the breast. Cancer, v. 43 p. 2370-6, 1979.

3. EARN, Y. et al. Breast carcinomas with choriocarcinomatous features: case reports and review of the literature. Breast J, v. 8, n. 4 p.2 44-8, 2002.

4. FATTANEH, A. Pathology of the breast. NY: Tavassoli Publishers, 1999.

5. GIANNOTTI, F. O. et al. Breast cancer with choriocarcinomatous and neuroendocrine features. São Paulo Med J, v. 119, n. 4, p. 154-5, 2001.

6. LEE, A. K. et al. Tumor marker expression in breast carcinomas and relationship to prognosis. Am J Clin Pathol, v. 84 p. 687-96, 1985.

7. RESETKOVA, E. et al. Breast carcinoma with choriocarcinomatous features. Ann Diagn Pathol, v. 8 n. 2, p. 74-9, 2004
8. ROSEN, P. P. Rosen's breast pathology. NY: Lippincott, Williams \& Wilkins Publishers, 2001

9. SAIGO, P. E.; ROSEN, P. P. Mammary carcinoma with "choriocarcinomatous" features. Am J Surg Pathol, v. 5, n. 1, p. 773-8, 1981.

10. SCHMITT, F. Carcinomas basais da mama: como abordá-los para o diagnóstico e indicação terapêutica. 1997. Tese de doutoramento - Instituto de Patologia e Imunologia Molecular da Universidade do Porto (IPATIMUP). Faculdade de Medicina da Universidade do Porto, 1997.

11. SIDDIQUI, N. H. et al. Fine: needle aspiration biopsy of a case of breast carcinoma with choriocarcinomatous features. Diagn Cytophatol, v. 34, n. 10, p. 694-7, 2006.

12. TORNNEY, D. C. et al. Biologic markes in breast carcinoma and clinical correlations with human chorionic gonadotropin. Cancer, v. 39, p. 2391-6, 1977.

13. WOODARD, B. H. et al. Adrenocorticotropin production by a mammary carcinoma. Cancer, v. 47 p. 1823-7, 1981. 